international news

A controversial scheme to explode a string of nuclear devices underneath the Colorado Rockies to extract vast deposits of natural gas has run into a critical snag. A key test of the technique, a 90-kiloton blast called Rio Blanco which was set off last year amid a storm of protest, has turned out to be something of a flop, and officials of the Atomic Energy Commission (AEC) are now trying to find out what went wrong.

The gas is trapped in small pockets in a layer of sandstone about a mile underground, and there is reckoned to be enough under the Rocky Mountains to supply the entire demand in the United States for about 10 years. But the sandstone is not porous enough to allow the gas to be extracted simply by drilling into it, and so the AEC together with an industrial partner, has been trying to free the trapped gas by smashing the rock with nuclear explosives.

The idea is to fire off a nuclear device in the gas-bearing sandstone, which creates a large underground cavern and fractures the surrounding rock for hundreds of feet in all directions. Gas then seeps into the cavern through the fractures and it is later pumped to the surface.

Rio Blanco was the third test of the technique, but it was the first to employ a radically new idea to improve the gas yield. Instead of firing off a single nuclear device, three explosives were placed in a vertical line, about 450 feet apart, and triggered simulianeously. The hope was that the caverns produced by each explosion would link up to form a huge cylindrical chimney in the sandstone layer, about 150 feet in diameter

\section{Rio Blanco draws a blank}

Colin Norman, Washington

and 1300 feet deep, surrounded by massive fractures radiating out words.

But earlier this year, when the AEC began to extract gas from the chimney, it found that it was getting a yield only from the cavern created by the topmost explosion-somehow, the caverns either failed to link up or they had later become sealed off from each other.

Asked last week what went wrong, J. Keith Davey, an AEC official concerned with the project, said that several things could have hapened. The simplest explanation is that the explosives were placed too far apart so that the caverns they created just didn't join up, but another possibility is that the chimney could have become blocked.

It is possible that the glassy melt formed by the intense heat of the nuclear explosions didn't fall to the bottom of the chimney, but blocked off the connection between the caverns. Another likelihood is that the rocks simply shifted after the explosions as Davey point out, underground mechanics at that depth are not well understood. Still another possibility is that the chimney could have been disturbed when the borehole was sunk into it to pump the gas to the surface, a suggestion which is given some credence by the fact that about 12,000 barrels of lubricating mud were lost during the reentry operation.

Later this year an attempt may be made to sink an oblique shaft into the second cavern to try to provide some answers, but whatever went wrong the failure has greatly damaged the chances that nuclear gas stimulation-as the technique is called-will ever be turned into a commercial venture. The scheme has already run headlong in spirited opposition from several diverse groups, and technical problems at this stage could well send it to an early grave.

Rio Blanco itself was entirely an experimental test, but what is worrying opponents of nuclear stimulation is the prospect of a full-fledged commercial venture. To exploit the gas field under the Colorado Rockies entirely would require several thousand nuclear blasts, a prospect which pleases neither the people living in the area nor the oil companies who are hoping to produce oil from the shale fields which happen to sit immediately above the gas-bearing sandstone.

A repeat of the Rio Blanoo test would be sure to attract a huge amount of opposition, particularly in view of the fact that two oil companies have just paid nearly $\$ 210$ million for the right to set up a prototype oil shale process on a small strip of federal land not for from the Rio. Blanco test site. Alternatively, the AEC would be hard put to justify moving to a pilot scale nuclear stimulation operation on the basis of the Rio Blanco results. The failure is thus a critical blow to the whole enterprise.

\section{Cash on the rail}

Rail from Ascension Island, drawn

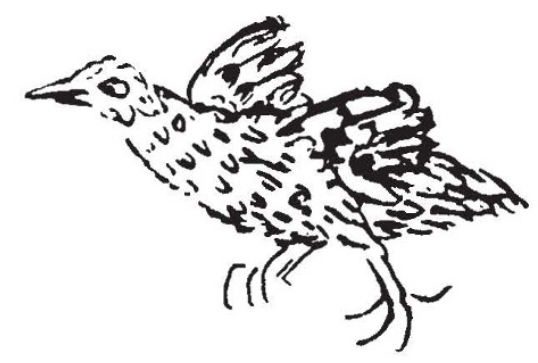

WHEN does specimen collection of rare birds and animals for scientific study become unacceptable? This question has been exercising ornithologists on both sides of the Atlantic recently. The trouble seems to arise when enthusiastic ornithologists and museum staff visit remote places and offer cash and other inducements to the natives for rare birds dead or alive.

The most recently reported case concerned a member of the American National Museum of Natural History of the Smithsonian Institution, who, during a visit to $\mathrm{St}$ Helena for the admirable purpose of studying the fossil remains of flightless rails, admitted offering cash rewards after the natives re- ported the presence of a living bird of this type. No specimen was in fact forthcoming and the author says that he is convinced that the bird was imaginary. But he might remember Charles Kingsley: "no one has the right to say that no water babies exist, till they have seen no water babies existing; which is quite a different thing, mind, from not seeing water babies".

Elsewhere in his article, the author says that the flightless birds of these remote islands were certainly only made extinct after men arrived. The Smithsonian seems to be following the Victorian idea that an animal is not discovered until it is safely stuffed in a museum. 